\title{
Joint inversion of ground based and helicopter-borne electromagnetic data
}

\author{
Sudha ${ }^{1}$, Bülent Tezkan ${ }^{1}$ and Bernhard Siemon ${ }^{2}$ \\ ${ }^{1}$ Institute für Geophysik und Meteorologie, Universität zu Köln \\ ${ }^{2}$ Bundesanstalt für Geowissenschaften und Rohstoffe, Geozentrum Hannover
}

\begin{abstract}
:
The use of ground-based electromagnetic methods (Transient Electromagnetics (TEM) and Radiomagnetotellurics (RMT)) is increased in last decades for hydrogeological purposes. However, airborne electromagnetic methods were also proposed as a possible tool for near surface investigations due to the capability to cover large areas in short time. By jointly inverting different kinds of geophysical measurements at a site, the ambiguity inherent in different geophysical methods can be avoided. In order to couple spatial data from frequency-domain helicopter-borne electromagnetics (HEM) with electromagnetic measurements from ground geophysics, a common 1D joint inversion algorithm for HEM, TEM and RMT data is developed. The depth of investigation of HEM data is rather limited compared to time-domain EM sounding methods on the ground. In order to improve the accuracy of model parameters of shallow depth as well as of the deeper crust, the HEM, TEM, and RMT measurements are combined using numerical joint inversion methodology. The 1D joint inversion algorithm is verified for the synthetic data of HEM, TEM and RMT. The proposed concept of the joint inversion takes advantage of each single method, which provides the capability to resolve near surface (RMT) and deeper electrical conductivity structures (TEM). Furthermore, the joint inversion is realized for the field data (HEM and TEM) measured in the Cuxhaven area, Germany.
\end{abstract}

Keywords: Joint inversion, helicopter-borne electromagnetics, transient electromagnetics, radiomagnetotellurics.

\section{INTRODUCTION}

Geophysical data inversions often suffer from uncertainties and non-uniqueness. To obtain a unique and meaningful model, inverted models are constrained by using the information from various sources. The constraints could be the information from the local geology and lithology, sequential and joint inversion of two or more data sets belonging to the same structure. As the sensitivity of two data sets for resistive and conductive structures is different, therefore, the joint inversion helps in overcoming the limitations of two data sets.

Auken et al. (2006) have discussed the current trends in near-surface electrical and electromagnetic methods and briefly summarized the rapid improvements in electrical and electromagnetic methods in past few decades. Applications of TEM and DC resistivity as well as airborne electromagnetic methods were reviewed by several authors (Matias et al. 1994, Nobes 1996, Pellerin 2002, Tezkan 1999, Siemon et al. 2009, Harinarayana 1999) for solving variety of problems related to hydrogeological investigations. For the simple geological structure, where 
one dimensional models are fairly valid for actual representation of the earth structures, these methods suffer from inherent difficulties in establishing layer thicknesses and resistivities from the measured data alone. Ambiguities in inversion, non-uniqueness and electrical equivalence are the common problems associated with these methods. These problems can be minimized either by constraining the inverted model by a-priori information or by using joint inversion of two or more independently generated data sets. In joint inversion, inherent weakness of one type of data set is compensated by the strength of the other data set (Raiche et al. 1985, Vozoff and Jupp 1975). Thus, the joint inversion can improve the inverted model and also reduces the nonuniqueness in the final model. This has been demonstrated by Vozoff and Jupp (1975) for magnetotelluric (MT) and Schlumberger soundings, and Gómez-Treviño and Edwards (1983) for controlled-source EM with Schlumberger sounding.

As EM methods are based on the propagation of EM fields, both, ground-based and airborne electromagnetic (AEM) measurements are feasible. Recent examples for helicopter-borne groundwater investigations with frequency-domain systems are given in Siemon et al. (2004; 2007) and Steuer et al. (2008), and with time- domain systems in: Jørgensen et al. (2006), Kjærstrup and Erfurt (2006), and Scheer et al. (2006).

Different EM methods can be jointly used to reduce the layer equivalences, which are an inherent problem in EM modeling, and thus enhance model resolution. Meju et al. (1999) combined vertical electrical soundings (VES), TEM and audio magnetotellurics (AMT) to map an aquifer in the Parnaiba Basin in the northeast of Brazil and showed that a combination of different methods helps to overcome the equivalence problem. HEM and TEM have been successfully combined for hydrogeological investigations, e.g., by Fitterman and Deszcz-Pan (2001) for saltwater mapping in the Everglades National Park in Florida, USA, and by Stadtler et al. (2004) for groundwater studies in Namibia.

In the present paper, the joint application of ground-based and helicopter-borne electromagnetic methods is used. The focus of this work is the joint inversion of ground-based and airborne electromagnetic methods. The idea is that the capability to resolve the near surface structures with RMT method is higher; however, deeper electrical conductivity structures can be well resolved by TEM. On the other hand, HEM provides better lateral coverage. Therefore, the joint inversion of HEM, TEM and RMT would yield quasi-2D images of the electrical conductivity over a large depth interval along a profile.

\section{THEORY}

Equivalence is a well known problem in the interpretation of electromagnetic data. Therefore, it can happen that the individual inversion results of different methods are different. In that case, it is difficult to combine these results. Joint inversion of these data sets is likely to give more consistent and reliable results in comparison with the individual inversion of these data sets. In literatures two different approaches have been used for joint inversion: first is sequential or multi-sequential inversion in which the output of one data set is used as an input for the other set to constrain the inverted model (Jupp and Vozoff, 1975). This is not a joint inversion in the strict sense. The second approach jointly inverts different data sets belonging to the same subsurface structure. For this purpose the objective function is defined by adding the error functional corresponding to the different data sets (Jupp and Vozoff, 1975, Kaikkonen and Sharma, 1998). 
To obtain this, the data sets, the model functions and the Jacobian matrices of these methods are combined to acquire only one set of model parameters.

$$
\mathbf{y}=\left(\begin{array}{c}
\mathbf{y}(H E M) \\
\mathbf{y}(R M T) \\
\mathbf{y}(T E M)
\end{array}\right), \quad \mathbf{J}=\left(\begin{array}{c}
\mathbf{J}_{1}(H E M) \\
\mathbf{J}_{2}(R M T) \\
\mathbf{J}_{3}(T E M)
\end{array}\right), \quad \mathbf{f}=\left(\begin{array}{c}
\mathbf{f}_{1}(H E M) \\
\mathbf{f}_{2}(R M T) \\
\mathbf{f}_{3}(T E M)
\end{array}\right)
$$

where $\mathbf{y}$ is the measured data vector and $\mathbf{f}$ is the computed response, and $\mathbf{J}$ is the Jacobian matrix. The Jacobian matrix is the parameter sensitivity matrix.

An important point in the joint inversion is the weighting of the used measuring methods with respect to each other. Appropriate weights are defined to the parameters influence matrix (Sensitivity matrix) for each data set (Vozoff and Jupp, 1975). The weight $\left(w_{i}\right)$ indicates the importance of $i^{\text {th }}$ data point and the resultant sensitivity matrix becomes

$$
J_{i j}=w_{i} \frac{\partial f_{i}}{\partial m_{j}} .
$$

For M-layer earth model with

$$
\begin{array}{ll}
\rho_{i} \geq 0 ; & i=1, \ldots, M+1, \\
h_{i}>0 ; & i=1, \ldots, M .
\end{array}
$$

In log domain, the parameters are

$$
\begin{aligned}
& x_{j}=\log \rho_{j} \quad \text { for } j=1, \cdots, M+1, \\
& x_{j+M+1}=\log h_{j} \quad \text { for } j=1, \cdots, M .
\end{aligned}
$$

The elements of the matrix, when we use relative errors, can hence be written as

$$
J_{i j}=w_{i} \frac{\partial f_{i}}{\partial m_{j}}=\frac{1}{f_{i}} \frac{\partial f_{i}}{\partial \log \rho_{j}}=\frac{\rho_{j}}{f_{i}} \frac{\partial f_{i}}{\partial \rho_{j}} .
$$

Or,

$$
\frac{1}{f_{i}} \frac{\partial f_{i}}{\partial \log h_{j}}=\frac{h_{j}}{f_{i}} \frac{\partial f_{i}}{\partial h_{j}}
$$

In this manner the Jacobian is made scale free, and since the relative error will be proportionate, different kinds of data will equally influence the correction that improves the current model (Vozoff and Jupp, 1975).

To analyze the stability of joint inversion, V-matrix, damped error bounds, damping factors and importances are used. These parameters are well-defined by Jupp and Vozoff (1975) and the same definition is used in the present work. 


\section{RESULTS}

The 1D numerical inversion codes (Scholl, 2005), which were developed by the Cologne geophysics group as a tool for the interpretation of individual methods (TEM, RMT), are extended to accomplish the 1D single and joint inversion with HEM data. Inversion of groundbased and helicopter-borne electromagnetic data is carried out using the two different strategies of inversion; Occam and Marquardt inversion. To obtain a reliable estimate of the model parameters, individual sounding data were initially inverted using Occam's inversion scheme. Occam's method with first and second order smoothness constraints generates overparameterized smoothest model from the measured data (Constable et al. 1987) using minimum norm inversion. For detailed analysis of the quality of inversion, Marquardt's inversion (Marquardt 1963, Levenberg 1944) technique was implemented using Singular Value Decomposition (SVD).

The 1D joint inversion algorithm for ground-based and helicopter-borne electromagnetic methods was first verified on the synthetic data and thereafter on field data. For this purpose, noise free synthetic data was generated for a five layered medium. The 1D single and joint inversion results for these data sets are discussed in the following sections.

\subsection{D joint inversion of synthetic HEM and TEM data}

At first, the joint inversion scheme is validated on synthetic HEM and TEM data derived for a five-layer model (Fig. 1(a) and 1(b)). The 1D Occam and Marquardt single and joint inversions were carried out for the data sets. No Marquardt inversion, however, was possible for HEM data of this example as the number of frequencies was less than that of model parameters. Here, 'Occam R1' and 'Occam R2' refers to the first and second order derivatives of smoothness constraints that were used in the Occam's inversion. In the zones, in which these two models were consistent and/or approximately the same, the obtained resistivity values were well resolved. The zones, where the two model results (Occam R1 and Occam R2) were not concurrent, were assumed as the unreliable zone.

The 1D single HEM inversion results for Occam's first and second order smoothness are consistent up to $80 \mathrm{~m}$ and infer a smooth model (Fig. 1(a)), which can be interpreted as fourlayer model. However, HEM could not see the last layer (fifth layer) and the thickness of the fourth layer was also not resolved. This is due to the limitation of the depth of investigation of the lowest frequency. On the other hand, the TEM inversion results for Occam's first and second order smoothness constraints are consistent up to $200 \mathrm{~m}$ depth and infer a smooth model, which can be well represented by five layers. This has been confirmed by Marquardt inversion as well.

SVD analysis indicates a five layer model for TEM sounding data. However, the inherent weakness to resolve near surface layer of TEM data is reflected in the inverted model, the importance of first layer resistivity (0.54). The importance values for third layer resistivity and thickness are 0.09 and 0.08 respectively, which indicates that the layer is irrelevant (Table 1).

The joint inversion result has significantly improved the small eigen values present in the individual inversions. A five layer model with same resistivity values for each layer was selected as starting model for joint inversion (Fig. 2). But from the SVD analysis the importance value for the resistivity and thickness of the third layer indicates that this layer is irrelevant. However, the 
first rather resistive (70 $\Omega \mathrm{m})$ and thin $(3 \mathrm{~m}$ ) layer was not resolved in the joint inversion due to the used frequency range for HEM. Therefore, only four layers were resolved in the joint inversion of HEM and TEM data. To resolve the first layer, it is required to use the shallow subsurface data, which can be measured from the other geophysical measurements suitable for shallow subsurface such as RMT.
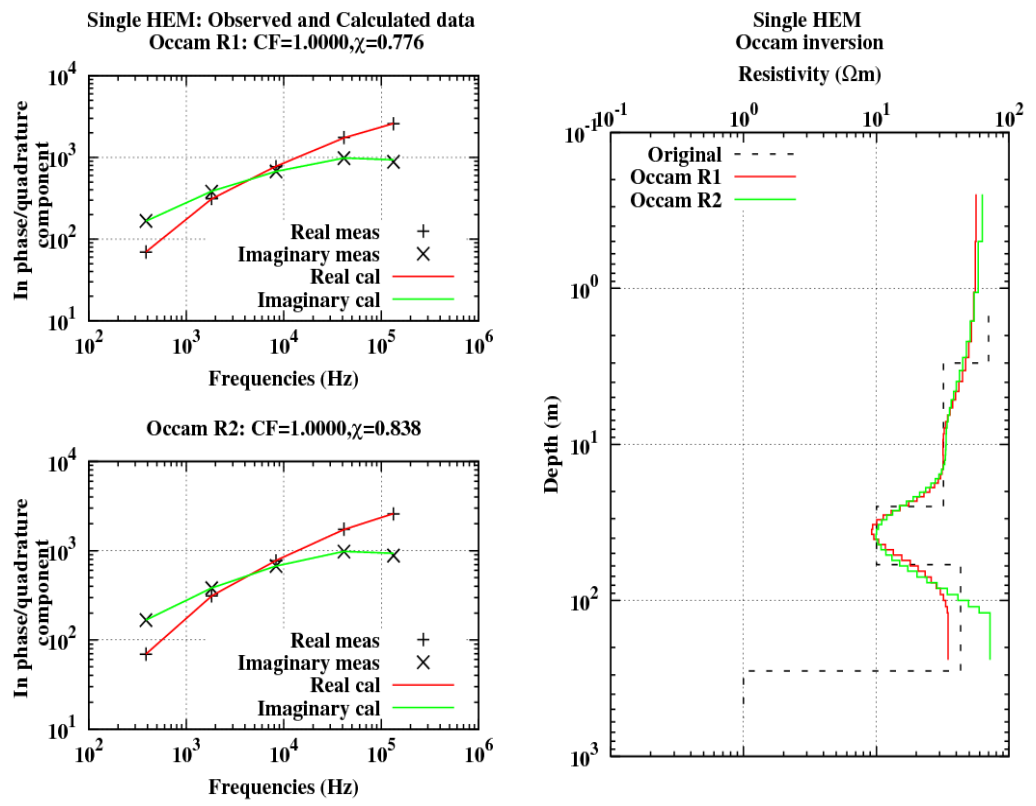

(a)
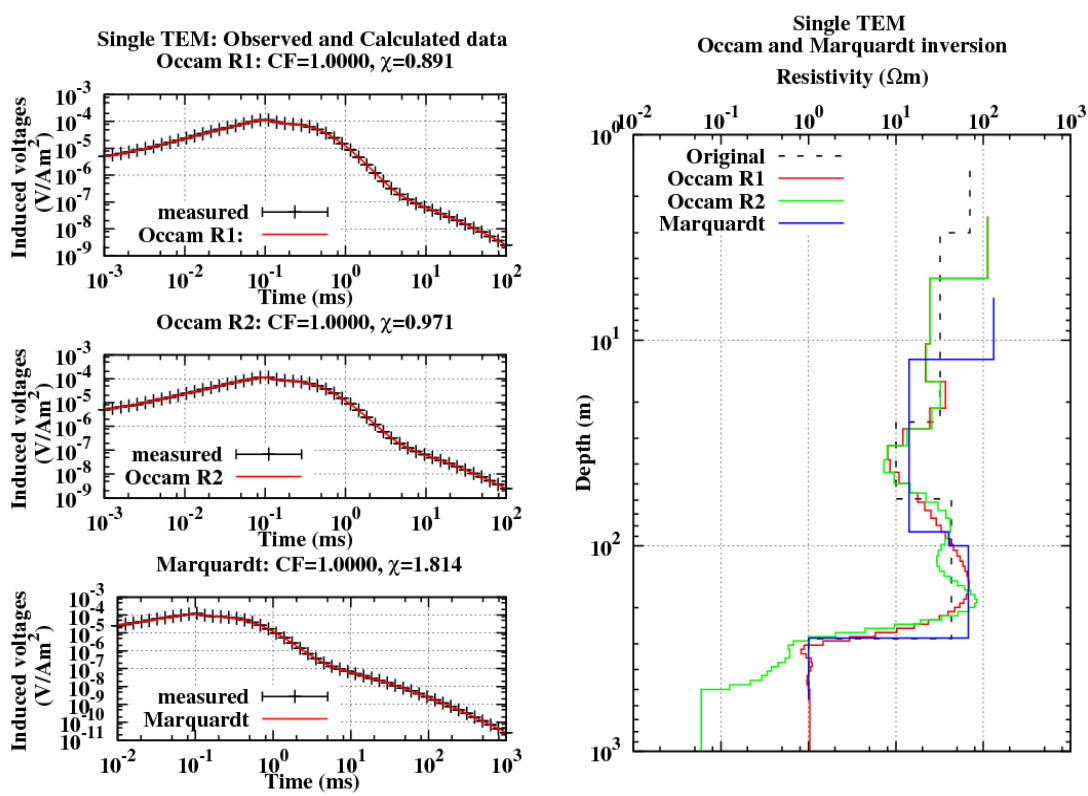

(b)

Figure 1: Synthetic five-layer model data and its fitting for single Occam and Marquardt inversion; (a) HEM and (b) TEM. 


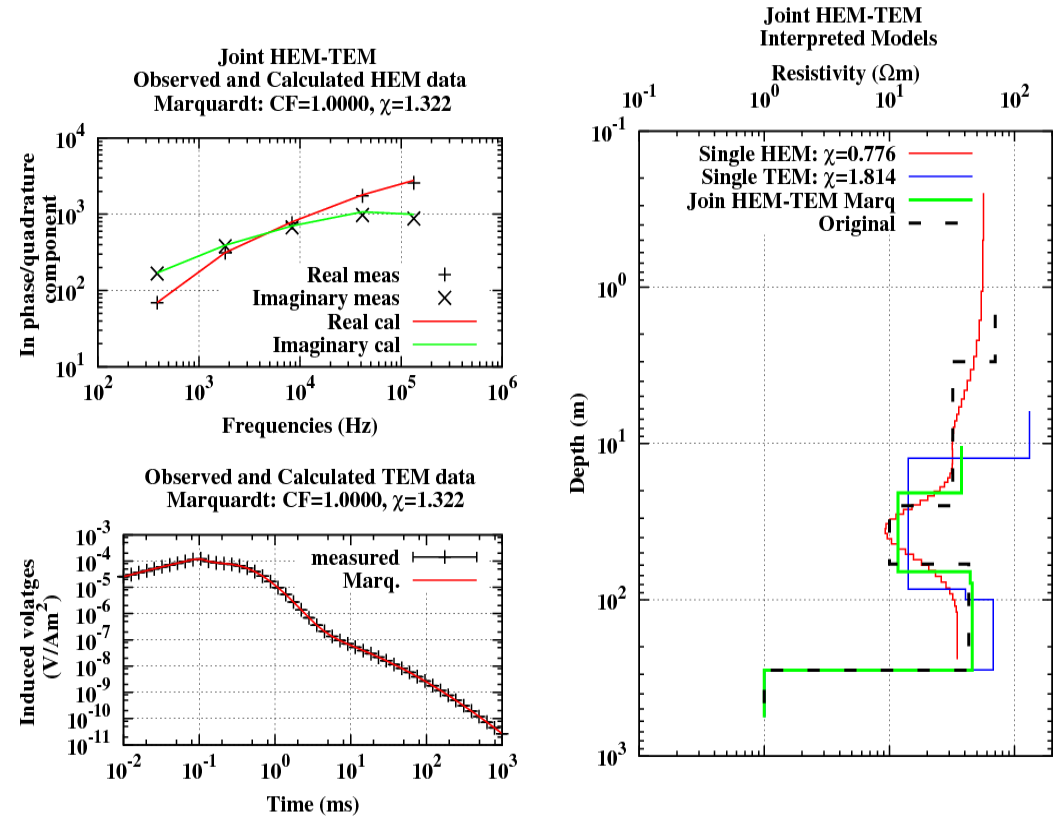

Figure 2: The joint inversion of HEM and TEM data and their fitting is displayed along with the original synthetic model.

Table 1: Model parameter and importance values for 1D Marquardt single (TEM and RMT) and joint (HEM-TEM and HEM-TEM-RMT) interpreted five-layer model.

\begin{tabular}{|c|c|c|c|c|c|c|c|c|}
\hline \multirow{2}{*}{$\begin{array}{l}\text { Original synthetic } \\
\text { model parameters }\end{array}$} & \multicolumn{2}{|c|}{$\begin{array}{l}\text { Single TEM inversion } \\
\text { result }\end{array}$} & \multicolumn{2}{|c|}{$\begin{array}{l}\text { Single RMT inversion } \\
\text { result }\end{array}$} & \multicolumn{2}{|c|}{$\begin{array}{c}\text { Joint HEM-TEM inversion } \\
\text { result }\end{array}$} & \multicolumn{2}{|c|}{$\begin{array}{c}\text { Joint HEM-TEM-RMT } \\
\text { inversion result }\end{array}$} \\
\hline & $\begin{array}{c}\text { Model } \\
\text { parameter } \\
\text { values }\end{array}$ & Importances & $\begin{array}{c}\text { Model } \\
\text { paramete } \\
\text { r values } \\
\end{array}$ & Importances & $\begin{array}{c}\text { Model } \\
\text { parameter } \\
\text { values }\end{array}$ & Importances & $\begin{array}{c}\text { Model } \\
\text { parameter } \\
\text { values }\end{array}$ & Importances \\
\hline$\rho_{1}=70 \Omega \mathrm{m}$ & 131.0584 & 0.5390 & 69.5021 & 0.9994 & 37.5017 & 1.0000 & 61.4740 & 1.0000 \\
\hline$\rho_{2}=32 \Omega \mathrm{m}$ & 14.1269 & 0.9993 & 32.2785 & 0.9993 & 11.6988 & 0.9964 & 29.8819 & 1.0000 \\
\hline$\rho_{3}=10 \Omega \mathrm{m}$ & 40.3728 & 0.0884 & 11.3787 & 0.7815 & 44.2405 & 0.0873 & 9.5836 & 0.9940 \\
\hline$\rho_{4}=43 \Omega \mathrm{m}$ & 67.3762 & 0.7003 & 20.4584 & 0.0256 & 45.7891 & 0.9804 & 40.2462 & 0.9945 \\
\hline$\rho_{5}=1 \Omega \mathrm{m}$ & 1.0050 & 1.0000 & 20.2444 & 0.0092 & 1.0010 & 1.0000 & 0.9942 & 0.9999 \\
\hline $\mathrm{h}_{1}=3 \mathrm{~m}$ & 12.3944 & 0.9987 & 3.0130 & 0.9966 & 20.7141 & 0.9972 & 4.8476 & 0.9999 \\
\hline $\mathrm{h}_{2}=22 \mathrm{~m}$ & 73.1684 & 0.9831 & 23.4694 & 0.9940 & 45.4053 & 0.9757 & 21.2994 & 0.9983 \\
\hline $\mathrm{h}_{3}=34 \mathrm{~m}$ & 14.2965 & 0.0759 & 20.2348 & 0.0718 & 12.2806 & 0.0627 & 30.3809 & 0.9750 \\
\hline $\mathrm{h}_{4}=224 \mathrm{~m}$ & 181.2711 & 0.9938 & 20.0192 & 0.0003 & 204.4274 & 0.9970 & 227.6416 & 0.9996 \\
\hline
\end{tabular}

\subsection{D joint inversion of synthetic HEM, TEM and RMT data}

To resolve the shallow subsurface structure, the code has been extended for the joint inversion of HEM-TEM-RMT (Fig. 3(a) \& (b)). Same five-layer model was used to generate noise free synthetic RMT data. To avoid the repetition of the same information, the individual HEM and TEM inversion results are not presented again. The individual RMT inversion shows better matching with the original model for the upper layers. The inversion of RMT from Occam's first 
(Model R1) and second (Model R2) order smoothness constraints (Fig. 3(a)) shows that the models start deviating after $20 \mathrm{~m}$ depth, which indicates the maximum depth $(20 \mathrm{~m})$ up to which the inverted models are reliable. The interpreted results of RMT data infer the three-layer model of the subsurface up to $20 \mathrm{~m}$. RMT data could resolve only a three-layer model due to the limited frequency range. All the model parameters corresponding to the top three layers are well resolved and represented by importance greater than 0.8 (Table 1).

Fig. 3(b) shows the 1D jointly inverted model of HEM, TEM and RMT data. Albeit the starting model was a homogeneous half-space, the interpreted model is in good agreement with the original model. It has improved the damping factor $(>0.96)$ and parameter importance $(>0.98)$. In the joint inversion all nine parameters are important in the five-layer model (Table 1). The error bounds for layer parameters (resistivities and thicknesses) are narrower, which indicate that the common error due to equivalence problem in the inversion of electromagnetic data has been reduced.

The correlation between the layer resistivities and thicknesses of the jointly inverted model to the original model has been significantly improved in the HEM-TEM-RMT joint inversion in comparison with the individual inversions except for the top layer. The first layer shows better fitting with the original model in case of individual RMT inversion in comparison with the joint inversion. This can be due to the bad fitting of the data for higher frequencies. As the same RMT data showed good fitting in individual inversion, while it got bad when jointly inverted with HEM and TEM data. In the previous section, however, we have already analyzed that the first layer was not resolved by any of the used methods (HEM, TEM). This shows that an appropriate weighting is necessary to enhance the model resolution from shallow to the deeper structures. We are still working on this theme.

\subsection{D joint inversion of HEM and TEM field data}

After successful validation of the joint inversion algorithm on synthetic data, it is applied to field data. No RMT field data are available from the sites, which were already investigated by HEM and TEM; therefore only the joint inversion of HEM-TEM is tested on field data (Fig. 4).

Field data, which have been used here, were archived and interpreted by BGR Hannover (Steuer, 2008). The aim of this survey was to deliver substantiated knowledge and understanding of the structural and hydraulic properties, to focus on the vulnerability due to surface contamination and other human impacts, and to investigate interactions with saltwater intrusions and other groundwater reservoirs.

Thirty nine pairs of HEM and TEM sounding data were selected from this area for individual and joint inversion. Individual Occam's inversion for HEM data infers a general three to four layer model (Fig. 4(a) \& (b)). Although, the reliability of the model is improved in the joint inversion, yet, it retains the general character of the model obtained from individual inversion. 

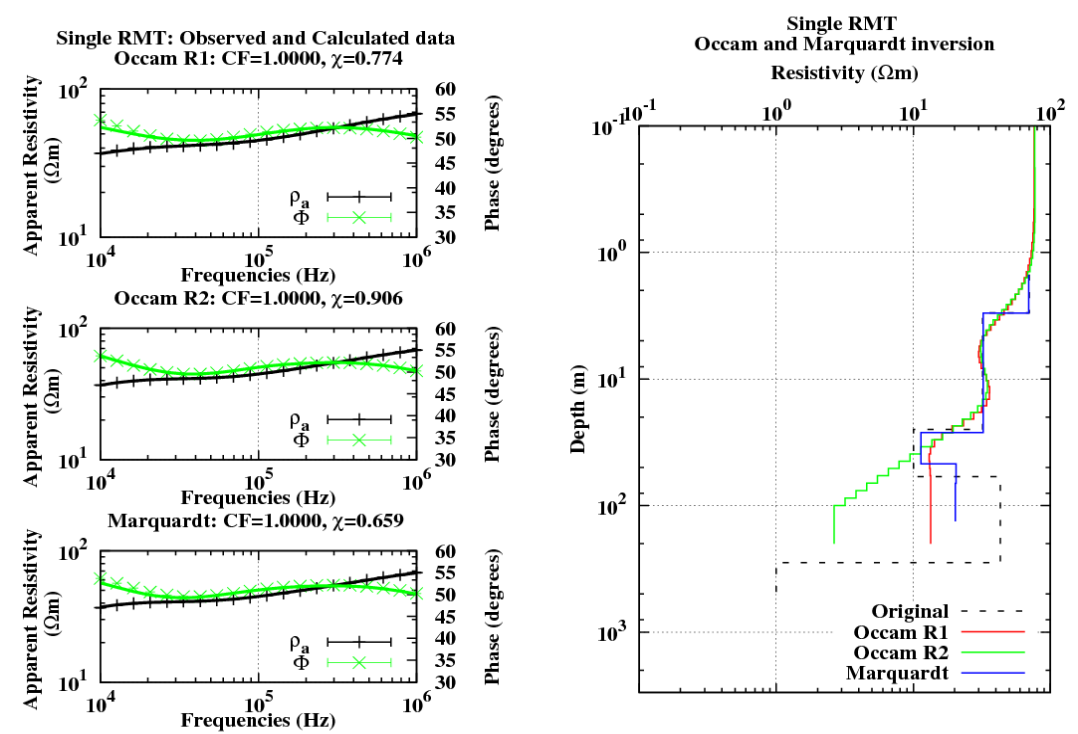

(a)
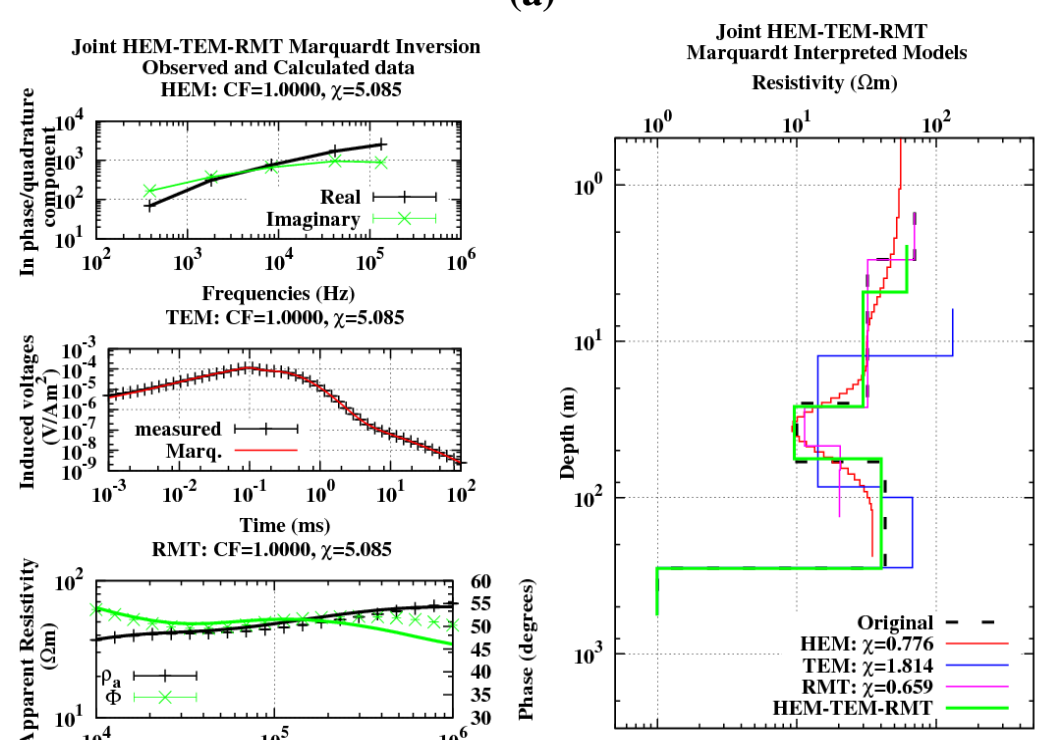

(b)

Figure 3: The synthetic five-layer model data and its fitting for single Occam and Marquardt inversion is shown in the upper plot (a) for RMT. The joint inversion of HEM, TEM and RMT data and their fitting is displayed in the lower plot $(b)$. 

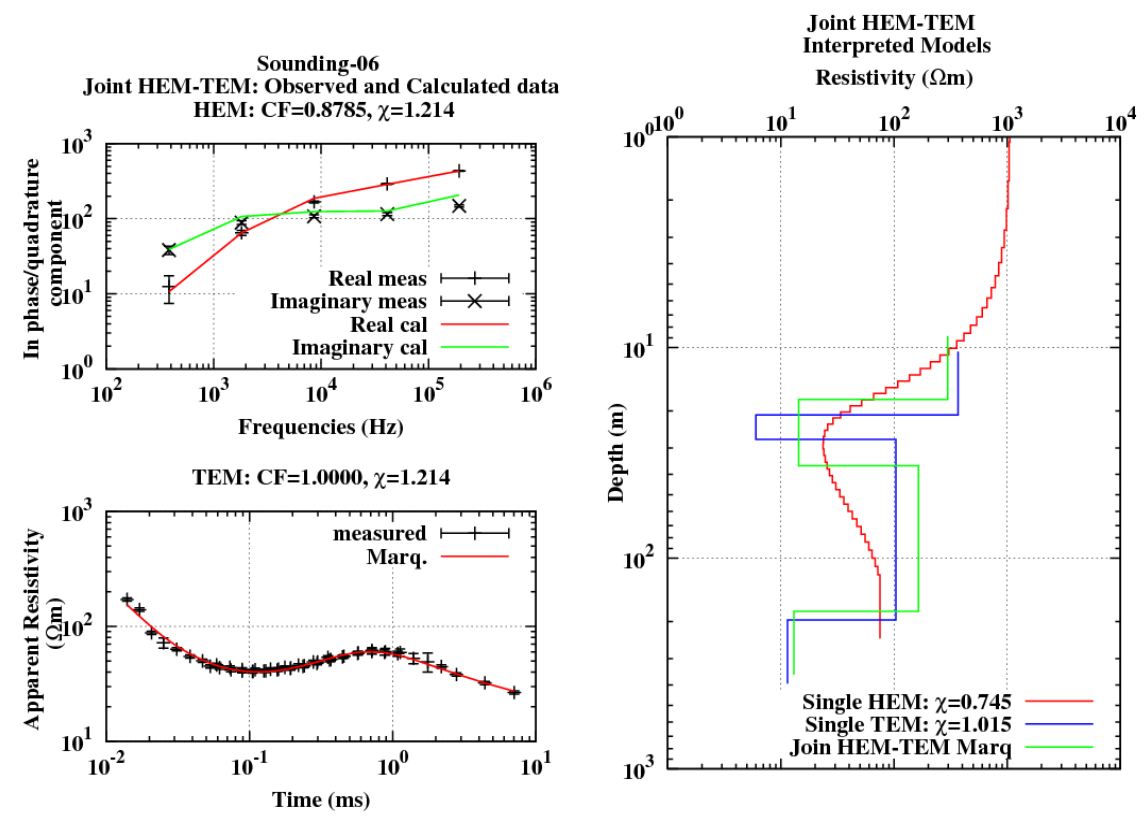

(a)

1D Marquardt joint interpreted models

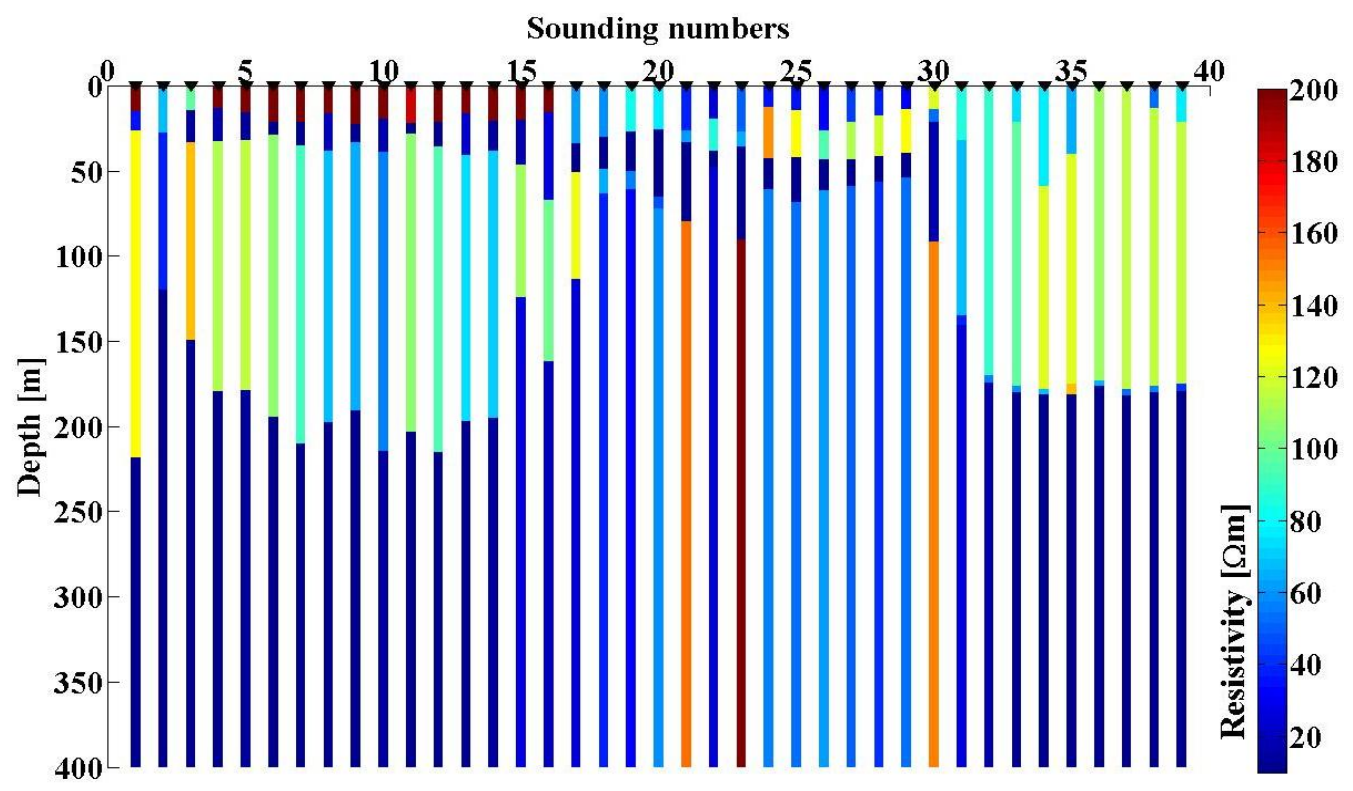

(b)

Figure 4: $1 D$ Marquardt joint inversion for HEM and TEM field data sets from Cuxhaven (Germany) measured by BGR (Steuer, 2008). The fitting of the HEM and TEM data is shown for one sounding as an example in the upper plot.

Similar SVD analysis was performed for all data sets. It has been found that the results are consistently improved in all cases for the joint inversion. The HEM and TEM data and its fitting is shown for one sounding as an representative example (Fig. 4(a)). 


\section{CONCLUSIONS}

The 1D numerical inversion codes, which have been used for the interpretation of single methods (TEM and RMT), are extended to do the single and joint inversion with HEM data. The joint inversion is tested for synthetic data (HEM, TEM and RMT) and field data (HEM and TEM). The resolution of model parameters is enhanced in joint inversion. To validate the code on field data, additional RMT measurements will be carried out on the sites, which were already investigated by HEM and TEM.

\section{REFERENCES:}

Auken E., Pellerin L., Christensen N. B. and Sørensen K., "A survey of current trends in nearsurface electrical and electromagnetic methods", Geophysics 71(5) G249 (2006).

Constable S. C., Parker R. L. and Constable C. G., "Occam's inversion: A practical algorithm for generating smooth models from electromagnetic sounding data", Geophysics 52(3) 289 (1987).

Fitterman, D. V. and M. Deszcz-Pan, "Using airborne and ground electromagnetic data to map hydrologic features in everglades national park", in Proceedings of the Symposium on the Application of Geophysics to Engineering and Environmental Problems SAGEEP 2001, Denver (Colorado), Environmental and Engineering Geophysical Society, 2001.

Gómez-Treviño E. and Edwards R. N., "Electromagnetic soundings in the sedimentary basin of southern Ontario - A case history", Geophysics 4(8) 311 (1983).

Harinarayana T., "Combination of EM and DC measurements for upper crustal studies", Surveys in Geophysics 20(3-4) 257 (1999).

Jørgensen F., Johnsen R., Pedersen J., Christensen J. F. and Sandersen P. B. E., "Tyrsting valley, in Groundwater Resources in Buried Valleys - a Challenge for Geosciences", edited by R. Kirsch, H.-M. Rumpel, W. Scheer, and H. Wiederhold, Chapter 5.2, 181-190, Leibniz Institute for Applied Geophysics (LIAG), Hannover, Germany, 2006.

Jupp D. L. B. and Vozoff K., "Stable iterative methods for the inversion of Geophysical data", Geophysical Journal of Royal and Astrnomical Society 42957 (1975).

Kaikkonen P. and Sharma S. P., "2-D nonlinear joint inversion of VLF and VLF-R data using simulated annealing", Journal of Applied Geophysics 39155 (1998).

Kjærstrup M. and Erfurt P., "Bording valley, in Groundwater Resources in Buried Valleys a Challenge for Geosciences", edited by R. Kirsch, H.-M. Rumpel, W. Scheer, and H. Wiederhold, 171-179, Leibniz Institute for Applied Geophysics (LIAG), Hannover, Germany, 2006.

Levenberg K., "A method for the solution of certain non-linear problems in least squares", Quarterly of Applied Mathematics 2164 (1944).

Marquardt D. W., "An algorithm for least-squares estimation of non-linear parameters", SIAM Journal on Applied Mathematics 11431 (1963). 
Matias M. S., Marques da Silva M., Ferreira P. and Ramalho E. "A geophysical and hydrogeological study of aquifers contamination by landfill", Journal of Applied Geophysics 32 155 (1994).

Meju M. A., Fontes S. L., Oliveira M. F. B., Lima J. P. R., Ulugergerli E. U. and Carrasquilla A. A., "Regional aquifer mapping using combined VES-TEMAMT/ EMAP methods in the semiarid eastern margin of Parnaiba, Brazil”, Geophysics 64(2) 337 (1999).

Nobes D. C., "Troubled water: Environmental applications of electrical and electromagnetic methods", Surveys in Geophysics 17393 (1996).

Pellerin L., "Applications of electrical and electromagnetic methods for environmental and geotechnical investigations", Surveys in Geophysics 23101 (2002).

Raiche A. P., Jupp D. L. B. and Vozoff K., "The joint use of coincident loop transient electromagnetic and Schlumberger sounding to resolve resistive layers", Geophysics $\mathbf{5 0} 1618$ (1985).

Scheer W., Kröger J., Kirsch R. and Zarth M., "Ellerbeker Rinne, in Groundwater Resources in Buried Valleys - a Challenge for Geosciences", edited by R. Kirsch, H.-M. Rumpel, W. Scheer, and H. Wiederhold, 205-226, Leibniz Institute for Applied Geophysics (LIAG), Hannover, Germany, 2006.

Scholl C., "The influence of multidimensional structures on the interpretation of LOTEM data with one-dimensional models and the application to data from Israel", $\mathrm{Ph}$. D. Thesis, Institute of Geophysics and Meteorology, University of Cologne, Germany, 2005.

Siemon B., Christiansen A. V. and Auken E., "A review of helicopter-borne electromagnetic methods for groundwater exploration”, Near Surface Geophysics 7629 (2009).

Siemon B., Eberle D. and Binot F., "Helicopter-borne electromagnetic investigation of coastal aquifers in North-West Germany", Zeitschrift für Geologische Wissenschaften 32(5/6) 385 (2004).

Siemon B., Steuer A., Meyer U. and Rehli H. J., "HELP ACEH-a post-tsunami helicopterborne groundwater project along the coasts of Aceh, Northern Sumatra", Near Surface Geophysics 5231 (2007).

Stadtler C., Fielitz F., Röttger B., Schildknecht F., Siemon B. and Voß W.,"Hubschrauber(HEM) und Transientelektromagnetische (TEM) Messungen zur Grundwassererkundung in Namibia", in Abstract Book of the 64th Annual Meeting of the German Geophysical Association (DGG 2004), Berlin, HGP09, 2004.

Steuer A., "Joint application of ground-based transient electromagnetics and airborne electromagnetic", Ph.D. Thesis, University of Cologne, 2008.

Steuer A., Siemon B. and Eberle D., "Airborne and Ground-based Elecrtomagnetic Investigations of the Fresh-water Potential in the T sunami-hit Area Sigli, Northern Sumatra", Journal of Environmental and Engineering Geophysics 13(1) 39 (2008). 
Tezkan B., "A review of environmental applications of quasistationary electromagnetic techniques", Surveys in Geophysics 20279 (1999).

Vozoff K. and Jupp D. L. B., "Joint inversion of Geophysical data", Geophysical Journal of Royal and Astronomical Society 42977 (1975). 